Central Washington University

ScholarWorks@CWU

Library Scholarship

James E. Brooks Library

6-22-2016

\title{
Web-Scale Discovery: Impact on Library Database Web Page Views and Usage
}

Zebulin Evelhoch

zebevelhoch@gmail.com

Follow this and additional works at: https://digitalcommons.cwu.edu/libraryfac

Part of the Library and Information Science Commons

\section{Recommended Citation}

Evelhoch, Z. (2016). Web-scale discovery: Impact on library database web page views and usage. Journal of Web Librarianship 10(3), 197-209. DOI: 10.1080/19322909.2016.1191048

This Article is brought to you for free and open access by the James E. Brooks Library at ScholarWorks@CWU. It has been accepted for inclusion in Library Scholarship by an authorized administrator of ScholarWorks@CWU. For more information, please contact scholarworks@cwu.edu. 
This is an electronic version of an article published in The Journal of Web Librarianship, available online at: http://www.tandfonline.com/toc/wjwl20/current

Evelhoch, Zebulin. 2016. "Web-Scale Discovery: Impact on Library Database Web Page Views and Usage” Journal of Web Librarianship 10(3): 197-209.

The version of record is available online at: http://dx.doi.org/10.1080/19322909.2016.1191048 


\title{
Web-Scale Discovery: Impact on Library Database Web Page Views and Usage
}

\author{
Zebulin Evelhoch \\ zeb.evelhoch@cwu.edu \\ James E. Brooks Library \\ Central Washington University \\ Ellensburg, Washington, USA
}

\begin{abstract}
Web page views of databases by title and databases by subject pages, in conjunction with COUNTER Database Report 1 and Journal Report 1 statistics, were examined to determine what impact a migration to Primo, a Web-scale discovery layer, had at Central Washington University Brooks Library. The analysis determined that the first year post-migration (2015) compared to the two years pre-migration (2013-2014) saw a decline in web page views of database web pages, journal full-text article requests, and database record views and result clicks. The implementation of Primo thus had a noticeable negative impact on both direct database access and overall electronic resource usage during the first year post-migration.
\end{abstract}

Keywords: Web-scale discovery, Ex Libris Primo, Academic Library, Database Usage, Website 


\section{Introduction}

Web-scale discovery layers changed the way libraries present their vast holdings and the way users discover and interact with those holdings. Bringing the discoverability of the majority of library resources into a single interface designed to be more consistent with what users are accustomed to from internet search engines has been championed, discussed, and refuted in many library circles at length. Nevertheless, the same questions remain: How do these discovery layers benefit end users and increase library usage? Given the amount of resources libraries spend, both financially and in staff time, on migrating to and implementing a new discovery layer, it is important to see how the investment benefits end users. The literature has explored the effect these interfaces have had on library staff time, workflows, discoverability, usefulness to various user groups, ability for users to locate needed information in interfaces with vast central indexes, and the ability for the library to promote the discovery layers as a one-stop shop for resource discovery to a wide range of users. In this paper, statistics are used to compare web page views of library web pages that serve as access portals to library databases in combination with COUNTER statistics at Central Washington University(CWU) to determine how migration to Primo, a Webscale discovery layer, affected use of electronic library resources. This analysis will help other libraries understand the effect migration to a discovery layer may potentially have on their online resources.

CWU, founded in 1891, is a mid-sized regional comprehensive public university that operates on the quarter system with its main campus located in Ellensburg, Washington. CWU has satellite campuses located throughout the state with two branch campuses located in Des Moines and Lynnwood. The University has an enrollment of over 10,000 students, with 92 percent coming from within the state of Washington, and offers over 135 majors, granting bachelor's and master's level degrees (Central Washington University n.d.).

This study specifically examines what impact, if any, migration to Ex Libris Primo, a Web-scale discovery layer, had on web page views of pages with links to library databases by title and subject, and full-text article requests, database result clicks, and record views over a one-year period post-migration in comparison with the two-year pre-migration period at CWU. Because Primo searches and provides results from a majority of library resources, the author's 
hypothesis was that usage of web pages through which databases are accessed would decline after implementation of Primo, while full-text article requests, record views, and result clicks would grow given the increased ease of discovering online resources.

The analysis determined database access through library web pages for databases by subject decreased significantly while web page views of databases by title also declined, though to a lesser extent. However, full-text article requests, record views and result clicks also all declined post-migration to Primo, contrary to the author's hypothesis. This finding shows that Web-scale discovery layers can cause a noticeable decline in the number of full-text article requests, record views and result clicks, and thus general usage of online resources.

In order to determine the impact the implementation of Primo had on database use at CWU, web statistics were examined to determine if page hits for web pages with databases by title and databases by subject increased, decreased or stayed consistent in comparison to the two years before and one year after migration. Full-text article requests, as measured by COUNTER Journal Report 1(JR1) Release 4(R4) in association with record views and result clicks from Databases Report 1(DB1) Release 4(R4) are examined over the same three-year period to further evaluate any influence the implementation of Primo had on database usage.

The analysis of the data and the results of this study will be valuable to academic libraries seeking to gauge the effect Primo (or other Web-scale discovery layers) has on database usage. This work will also help libraries determine the importance of promoting direct database links and other access points post migration. This study presents a unique and new perspective as it examines the effect a Web-scale discovery layer has on traditional access points for databases, such as web pages listing databases, in addition to database use following migration. This new research and analysis of the impact of Primo will prove beneficial to a variety of academic institutions interested in the impact Web-scale discovery has on the use of databases and traditional access points.

\section{Literature Review}

Academic libraries are faced with many challenges. One of the more pressing needs is to provide electronic access to their vast collections, which is especially vital considering that the majority of users who arrive at institutional databases do so from search engines, not via the library homepage or discovery layers (Gottfried 2011; Tilley 2013). But some librarians feel the 
introduction of Web-scale discovery layers "has the potential to radically change how users interact with and discover the wealth of information available within library collections" (Way 2010, 219).

Web-scale discovery layers represent a sea change from the past, as these new interfaces combine previously disparate systems such as catalogs, databases, and other electronic resources, meaning that users no longer need to select a specific tool to start their research (Condit Fagan et al. 2012). Many librarians believe that these comprehensive discovery layers serve only as a starting point, and are best for lower-level undergraduates, though they also recognize that they can bring resources from little used databases to the forefront, including often missed resources such as newspaper articles (Fawley and Krysak 2012; Kornblau, Strudwick, and Miller 2012). Other librarians are concerned that these broad discovery layers may "dumb down the research process" (Wang and Mi 2012, 242). Whatever librarians may feel, these discovery layers incorporate faceted navigation and relevancy rankings to assist users in finding materials in a way that is more similar to what users are accustomed to on the open web. Features include the ability to type a word into a single search box and receive many relevant results (Breeding 2012; Mahoney and Leach-Murray 2012). Lastly, and just as important, libraries have invested significant time and finances in these systems with the goal of providing the capability to discover all library resources from one search (Kornblau, Strudwick, and Miller 2012). Librarians must ensure they are being used to their fullest extent, as an increasing number of college students consider information from library sources to be more trustworthy than sources from search engines (De Rosa et al. 2011).

An analysis at Grand Valley State University Library found that usage of most databases, regardless of breadth, depth, or subject, decreased in the semester following migration to Summon, a Web-scale discovery layer (Way 2010). At Illinois State University, they found that most students were able to easily locate needed materials using EBSCO's Web-scale discovery layer, although the authors also cautioned that users will continue to need to access some databases directly as discovery layers cannot fill all the gaps and functionality needed by academic faculty (Williams and Foster 2011). The need to access specific databases for more advanced searching as compared to the broad services of a Web-scale discovery layer was supported in a study at Ryerson University in Toronto where it was found that students, both graduate and undergraduate, are most likely to use the resources their instructors recommend (Lundrigan, Manuel, and 
Yan 2015). This issue reinforces the need for libraries to market their resources and work with faculty to demonstrate how the library's discovery layer can meet their needs if the library wants to see increased usage.

Turning to Ex Libris Primo specifically, a study at Purdue University Libraries revealed users predominately performed keyword searches in Primo, which allows users to search the majority of a library's resources - print, digital, institutional repositories, and databases and other subscribed content (Niu, Zhang, and Chen 2014). However, these broad keyword-based searches can create problems for users searching via Primo for a specific resource that has a title with a general term because of the vast central index of resources Primo searches (Nichols et al. 2014). Consistent with results found with other Web-scale discovery layers, the University of Birmingham found that after migrating to Primo, users regularly linked out to other databases, thus further reinforcing the idea that for more advanced searching users cannot rely solely on Primo and must access specific databases directly (Bull, Craft, and Dodds 2014). While ideally Primo should make searching for library resources more efficient, user friendly, and accessible for a broader range of users, caution should be used, especially when considering more advanced users (Jarrett 2012). In summary, Primo and other Web-scale discovery layers may best match the needs of undergraduates and basic researchers, but do not meet the needs of graduate students and faculty (Lundrigan, Manuel, and Yan 2015; Nichols et al. 2014).

Web-scale discovery layers were developed and implemented to make it easier for users to discover needed resources within libraries' vast holdings. The literature examined shows that a variety of issues still exist that prevent users from finding the library holdings that will be most beneficial to them. In summary, dealing with these issues must start with recognition of the audience for these tools. Discovery layers best serve undergraduates doing basic research, which means faculty, graduate students, and others doing advanced research may still need to turn to specific databases. This lack of functionality to meet the needs of advanced researchers may lead to decreased use of discovery layers. In addition, this decrease in usage may be exacerbated through behaviors modeled by instructors. Students are most likely to use resources their instructors recommend, therefore if graduate students and professors do not use a discovery layer, they may be unlikely to recommend it to their students. Promotion of the discovery layer by the library staff can change these behaviors. Promotion and outreach by library staff can focus on how to quickly locate desired materials from the immense central indexes used by modern discovery 
layers, and can acknowledge that discovery layers cannot serve as a portal to all library resources. Seeing how the implementation of a discovery layer affects the usage of library databases and the access points to those databases can help libraries preparing for a migration ensure both their discovery layer and databases are promoted to all users. This strategy will enable users to locate the information they need and will make it more likely that library resources will still be used.

\section{Methodology}

On December 18, 2014 CWU Brooks Library went live with Ex Libris Primo as its discovery layer in combination with a migration to Ex Libris Alma, after a nearly six month migration from Innovative's Millennium and its associated OPAC. This migration was part of a transition to a shared hosted-library services platform and Web-scale discovery layer of the Orbis Cascade Alliance (Orbis Cascade Alliance 2015). As "go live" occurred during intersession, which was toward the end of the calendar year, it was logical to designate calendar years 2013 and 2014 as pre-migration and calendar year 2015 as post-migration. This designation allowed for two years of data on web page views, and database and journal usage pre-migration to be compared to one full year of post-migration data.

This study reviewed website statistics gathered from Advanced Web Statistics 7.4 (build 20150704) for January 2013 to December 2015 from CWU's Brooks Library's website. Web page views were recorded for each year over this time period for each of the following categories:

- Total Page Views,

- Databases by title Page Views (http://www.lib.cwu.edu/DatabasesByTitle), and

- Databases by subject Page Views (http://www.lib.cwu.edu/DatabasesBySubject).

These data was then analyzed to determine any year-to-year trends of views of the databases by title and databases by subject pages with total page views serving as a baseline comparison. The data was then compared to full-text requests of journal articles and database usage over the same period to further determine the influence a Web-scale discovery layer had on database usage and full-text requests. 
Journal and database statistics were compiled from EBSCOHost's EBSCONet Usage Consolidation platform using COUNTER Journal Report 1 (R4) and COUNTER Database Report 1 (R4). While these statistics do not cover all of CWU's journal and database usage, they contain the majority of databases, including the most used such as Academic Search Complete, Business Source Complete, Education Full Text, Newswires, and PsycINFO, among others. Additionally, journals included were from Wiley, Elsevier, Taylor \& Francis, Cambridge, Oxford, JSTOR, and Thomson Reuters, to list the more prominent vendors included in these statistics. The vendors and publishers included provide the vast majority of usage and thus an ample dataset to present an accurate usage picture, which can be used to determine if full-text requests and database usage increased, decreased, or stayed the same pre- and post-migration.

COUNTER Database Report 1 (R4) statistics were gathered, compiled, and examined for January 2013-December 2015 for record views and result clicks, providing additional points to determine any changes in usage in association with COUNTER Journal Report 1 (R4) full-text article request statistics. Record views, result clicks, and full-text article requests provided excellent statistics to determine any usage trends the migration to Primo had on database usage.

Record views and result clicks provide similar, though different data. Incorporating and evaluating both provides the most comprehensive picture of database use. Record views "report the number of times the detailed metadata of records within the database are viewed, regardless of whether these records are reached from a set of search/browse results from the platform or from a link-in from an external source" (COUNTER 2016, 3). Thus, whether a user clicks a link from Primo or the database itself, it is included in these statistics. Result clicks are "counted irrespective of whether it takes the user to an internal record within the database searched (e.g., full text or an abstract...), or to an external resource (e.g., an OpenURL link)" (COUNTER 2016, 3). Essentially, when a user finds a desired resource, a result click is counted whether the article is accessible in full-text online or if it is borrowed from another library through interlibrary loan.

It is worth noting that the student population at CWU, shown in Table 1, remained consistent throughout the period of January 2013-December 2015, thus student population size had no impact on any changes in resource or web page usage. 
Table 1: Student Enrollment - FTE (Point in Time: Census)

\begin{tabular}{|l|l|l|l|l|}
\hline & Winter & Spring & Summer & Fall \\
\hline 2013 & $9,988.81$ & $9,508.76$ & $2,530.52$ & $10,123.72$ \\
\hline 2014 & $9,866.35$ & $9,803.89$ & $2,468.89$ & $10,310.17$ \\
\hline 2015 & $9,714.97$ & $10,001.47$ & $2,501.03$ & $10,597.05$ \\
\hline
\end{tabular}

Source: Internal CWU Student Metrics Analytics Reporting Tool

\section{Results}

\section{Web Page Views}

Total web page views from January 2013 to December 2015, as shown in Figure 1, were fairly consistent, with usage slightly higher in 2013. Annual totals came to 2,181,929 page views in 2013, 1,666,377 in 2014 and 1,617,398 in 2015, showing a slight decrease in views from 2014 to 2015 . When looking at the two-year pre-migration average of 1,924,153 page views, there is a 15.94 percent drop in web page views in 2015; however, this was largely because of higher usage in 2013, with web page use remaining consistent between 2014 and 2015. The higher usage in 2013 could have been caused by a bot, or increased internal usage during a website review, though the reason for the higher usage rate was not clear from the usage statistics or institutional history. Based on the total web page views, no trend was discernable that could have directly influenced the number of views of the two pages used to access databases: databases by title and databases by subject.

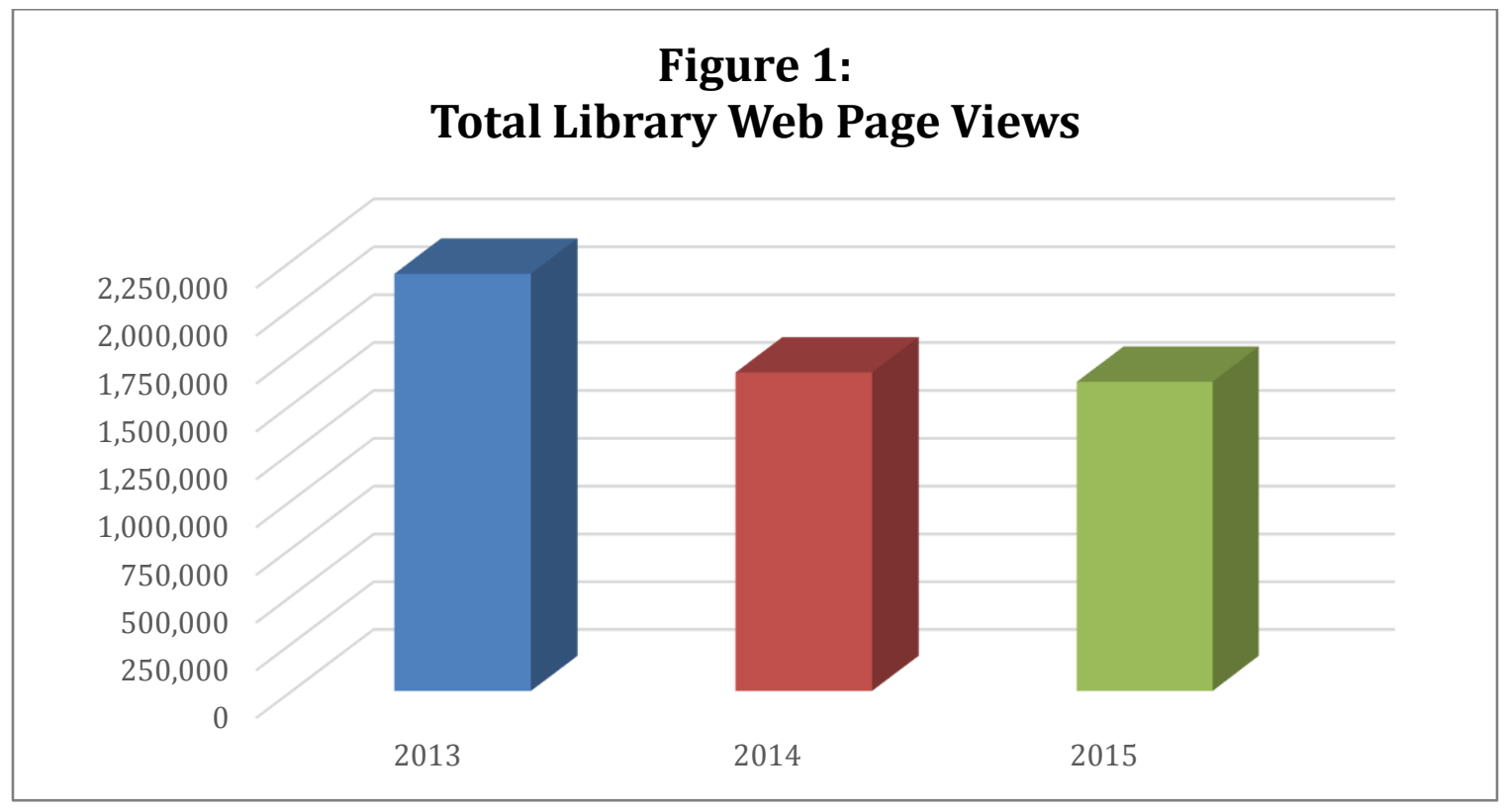


The databases by title page consistently received nearly twice as many views as the databases by subject page as an access point to library databases. From this evidence, it can be inferred that most users are at least familiar with the name of a single database, or feel confident finding one that can meet their needs through browsing by title. Both access points have sufficient usage for further separate analysis. Before continuing, it is worth noting that users who visit each of these access pages may not necessarily continue on to a database. Users may be unsure of what to do next, decide to return to the library homepage, discontinue their research, or any number of other scenarios. Given the consistent and high usage of these pages it appears likely that most users are continuing on to the resources contained within them.

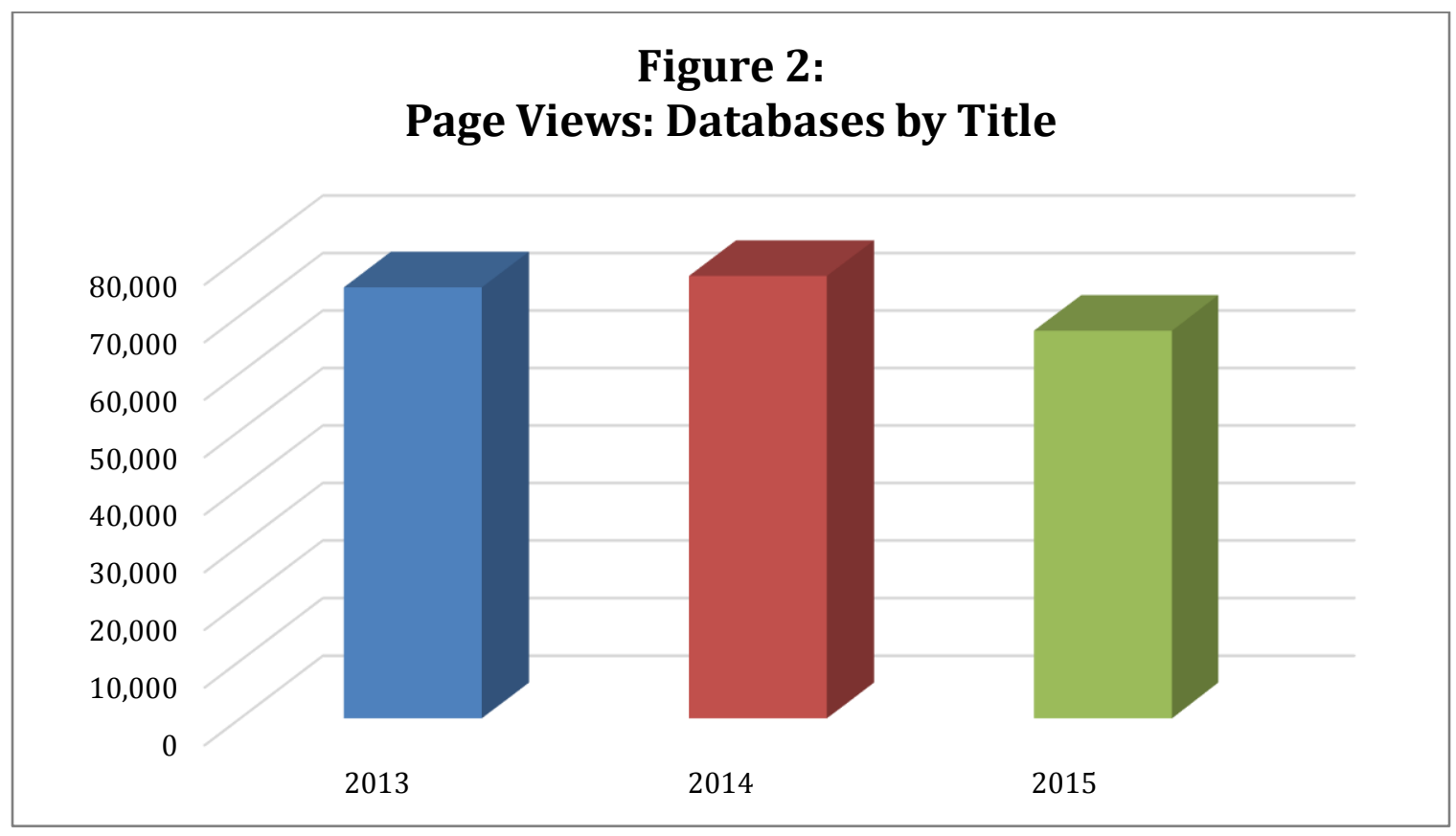

The data in Figure 2 show that usage of the databases by title page did fall by 11.26 percent to 67,315 total views in 2015 compared to an average of 75,858 views for 2013 and 2014. Presumably those users who knew specific databases to use, and who customarily accessed databases by the databases by title page were consistent in going directly to those databases instead of using Primo. A not insignificant amount of users were clearly turning elsewhere to discover the resources they needed, though it is unclear if they were turning to Primo, or to an external resource such as Google Scholar. Primo does appear to slightly influence the search habits of users who traditionally turned to specific databases accessed by the databases by title page, though many users continue to prefer going directly to a specific database. Choosing to navigate directly 
to a specific database may be due in part to some users' desire to continue to use an interface with which they are already familiar. Another possibility is that some users would like to access a resource that only provides content related to their subject area and does not include the many unrelated results that comprehensive Web-scale discovery layers often provide. This explanation is supported by findings at Illinois State University demonstrating that depending on the research topics, advanced researchers still turn to databases due to the functionality they provide (Williams and Foster 2011). In the year following Primo implementation, page views of databases by title dropped. Users may have turned to a variety of resources to find the information they needed in lieu of the databases by title page, with one possible explanation being that they performed searches using Primo, found the information they needed, and thus did not need to continue on to the databases.

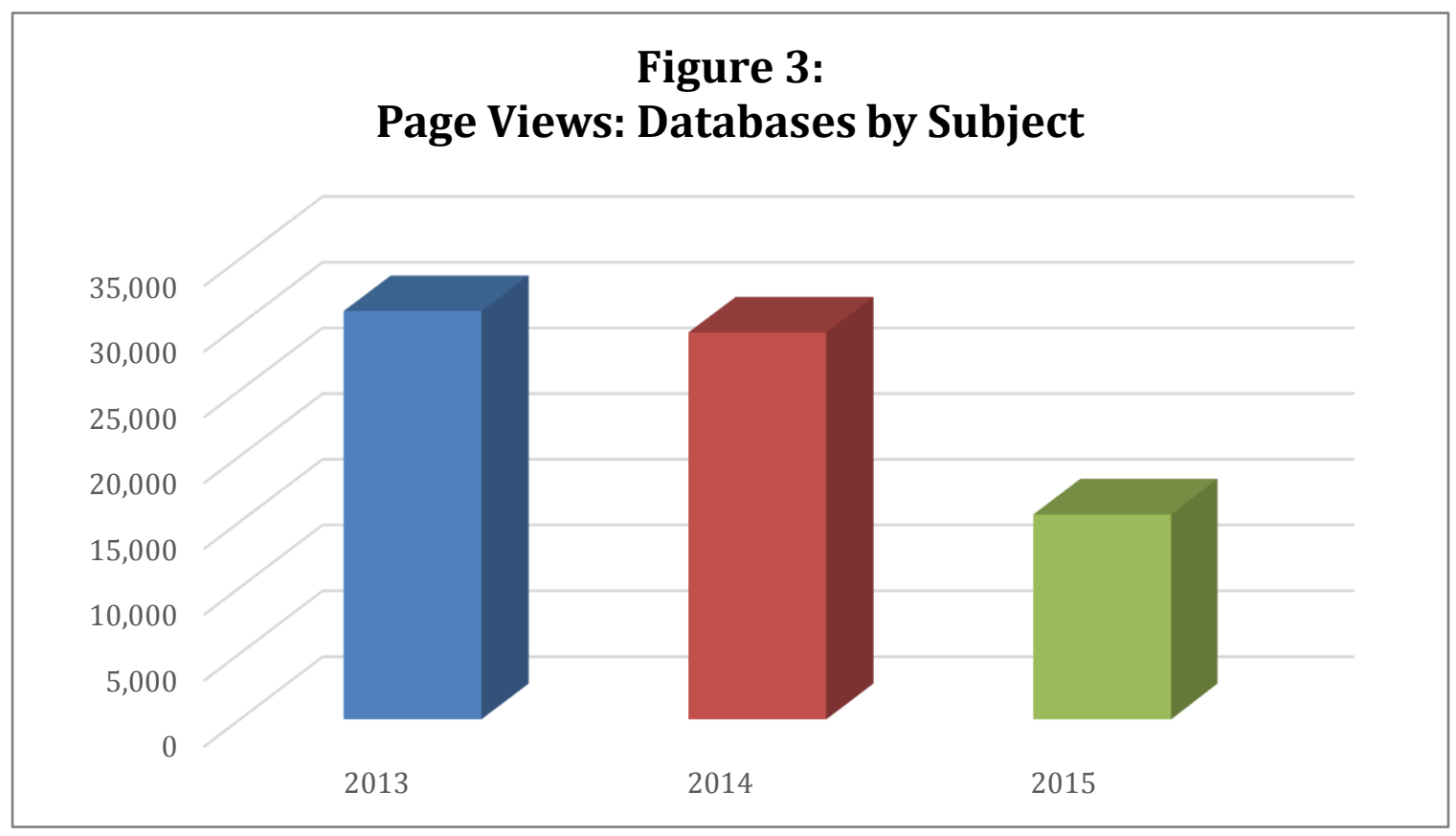

From the website page view statistics, it appears that users who are not as familiar with library databases and would traditionally browse the databases by subject page to locate databases and journal articles may now be searching for and discovering resources solely in Primo. This searching behavior would not be surprising considering Primo delivers a wide variety of results from a myriad of library holdings. The simplicity of searching all these holdings also makes Primo a useful starting point for entry-level searchers who may be unsure of where to begin a search (Lundrigan, Manuel, and Yan 2015). As shown in Figure 3, web page views of databases by subject decreased significantly in 2015, the year after CWU migrated to Primo. In the two 
years pre-migration, total annual web page views of databases by subject were 31,020 (2013) and 29,389 (2014), for a pre-migration average of 30,205. In stark contrast the first post-migration year, 2015, saw only 15,541 views of the databases by subject page, a 48.54 percent decrease. Most surprising is that a noticeable decrease in usage of the databases by subject web page occurred throughout the year including times when library staff had little time to promote the new discovery layer and instruct users on its use. Possibly, users performing basic searches via the more noticeable Primo single-search bar were locating needed information, whereas before users had to continue their search beyond the online catalog by also incorporating databases into their research, and those unfamiliar with library databases may have ventured to the databases by subject page to find needed information. From the page view statistics, it seems likely that Primo had a significant impact on the decline in the number of page views of databases by subject.

The value of Primo for users performing basic searches is reinforced when examining Primo usage data. In 2015, the initial year with Primo as the discovery layer, there were 262,810 searches performed via Primo. Of those searches, 217,805 (83 percent) used the basic singlesearch bar functionality while only 45,005 (17 percent) used the advanced search functionality. This finding shows that the majority of users who conduct a search in Primo are making use of the single-search bar access point.

Analysis of web page views has shown that overall web page views stayed consistent throughout the three-year period of January 2013 through December 2015. During that same period, views of the databases by title page dropped marginally while views of the databases by subject page showed a drastic decrease in views. These changes appear to correspond directly to the implementation of Primo, showing that a Web-scale discovery layer is able to provide comprehensive discoverability of resources that users need, especially those who in the past turned to listings such as those contained in the databases by subject web page to find resources not contained within the traditional catalog. Because Primo provides access to a wide variety of resources through its central index, users' needs are now met within Primo without the need to search individual databases (Nichols et al. 2014). A slight but noticeable drop in views of the databases by title page was also seen, showing that users who know the name of a specific database still primarily turn directly to those databases. This finding has been supported elsewhere, especially for upper-level researchers who are best served by using the databases which "allow more sophisticated and precise searching” (Kornblau, Studwick, and Miller 2012). It is also possible 
that users may search for and access a specific database using Primo, removing the need to navigate to the databases by title page. Additional research would be needed to see if users turn to those specific databases instead of accessing Primo, or in addition to using Primo.

\section{COUNTER Statistics}

In order to provide a comprehensive analysis of the impact of the migration to Primo, COUNTER statistics for the period January 2013 through December 2015 were examined. First, full-text article requests from COUNTER Journal Report 1 (R4) were examined. The author hypothesized that full-text article requests would increase post migration as more users would discover articles through Primo and thus view those articles; whereas prior to migration locating journal articles often took additional steps that some users may not have chosen to take. However, the COUNTER statistics demonstrate that full-text article requests did not increase. Fulltext article requests stayed consistent with previous years as shown in Figure 4. 292,671 full-text articles were requested in 2013 and 316,362 in 2014, for a two-year pre-migration average of 304,517. While full-text article requests did not significantly change in 2015, they did drop to 297,588, a 2.28 percent decrease over the previous two-year average. Full-text article requests were higher in 2015 than in 2013, but were lower than the two year pre-migration average.

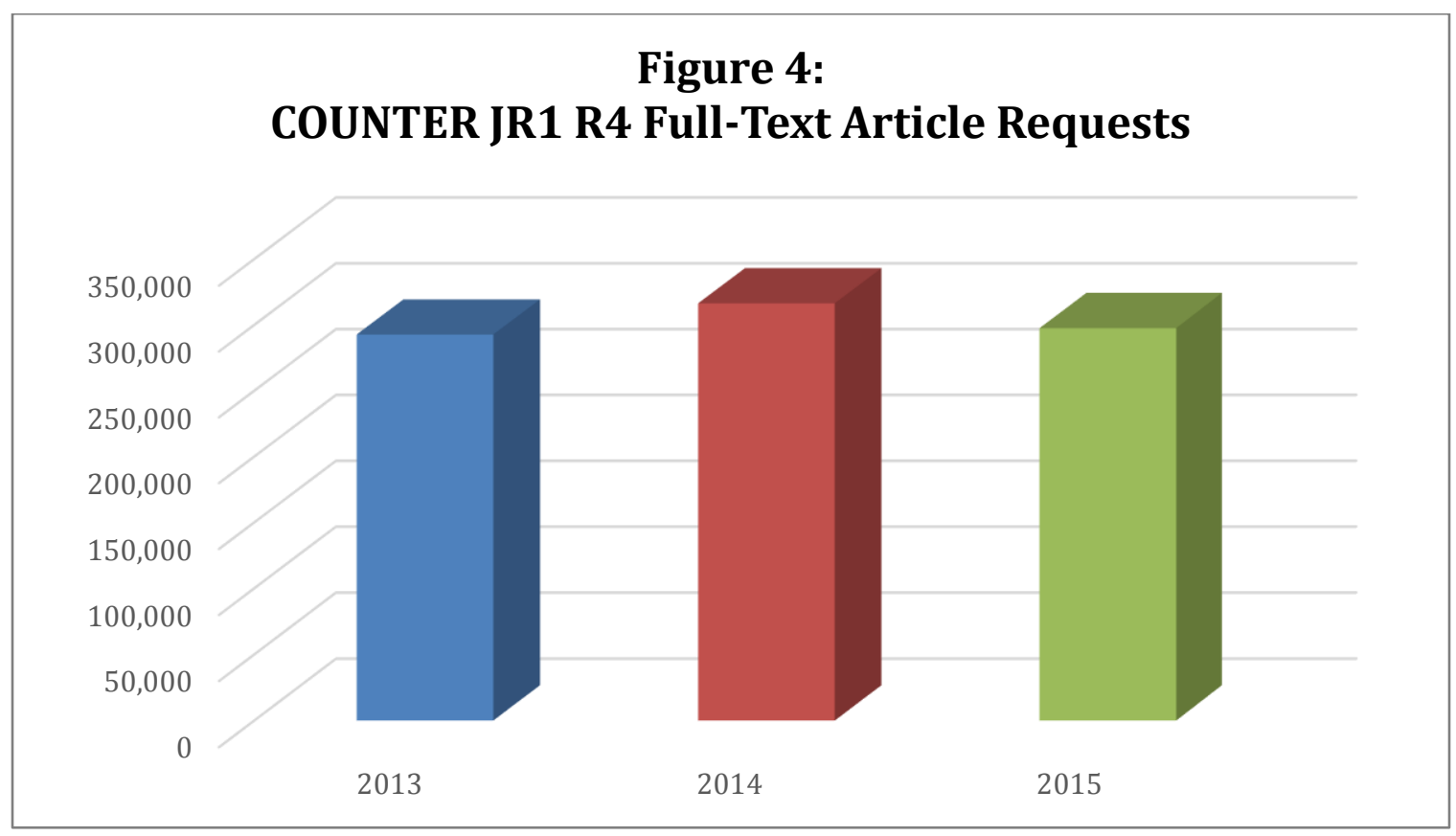

Additional research is needed to determine why full-text article requests experienced a downward trend, though one possible explanation may be that more users are turning to the open 
Internet to locate information. Another possibility for the decline in full-text article requests is that users may be unclear how to view or request journal articles using the Primo interface and abandoned their search altogether. Full-text article requests would have shown consistent use or an increase even if users were turning to specialized internet search engines, such as Google Scholar, to locate information as ultimately they would end up accessing the library resources to view the articles and thus be counted in this metric. The data do not support this, and instead indicates that perhaps if users are turning to search engines like Google Scholar for research, they are finding resources available on the open Internet that meet their needs.

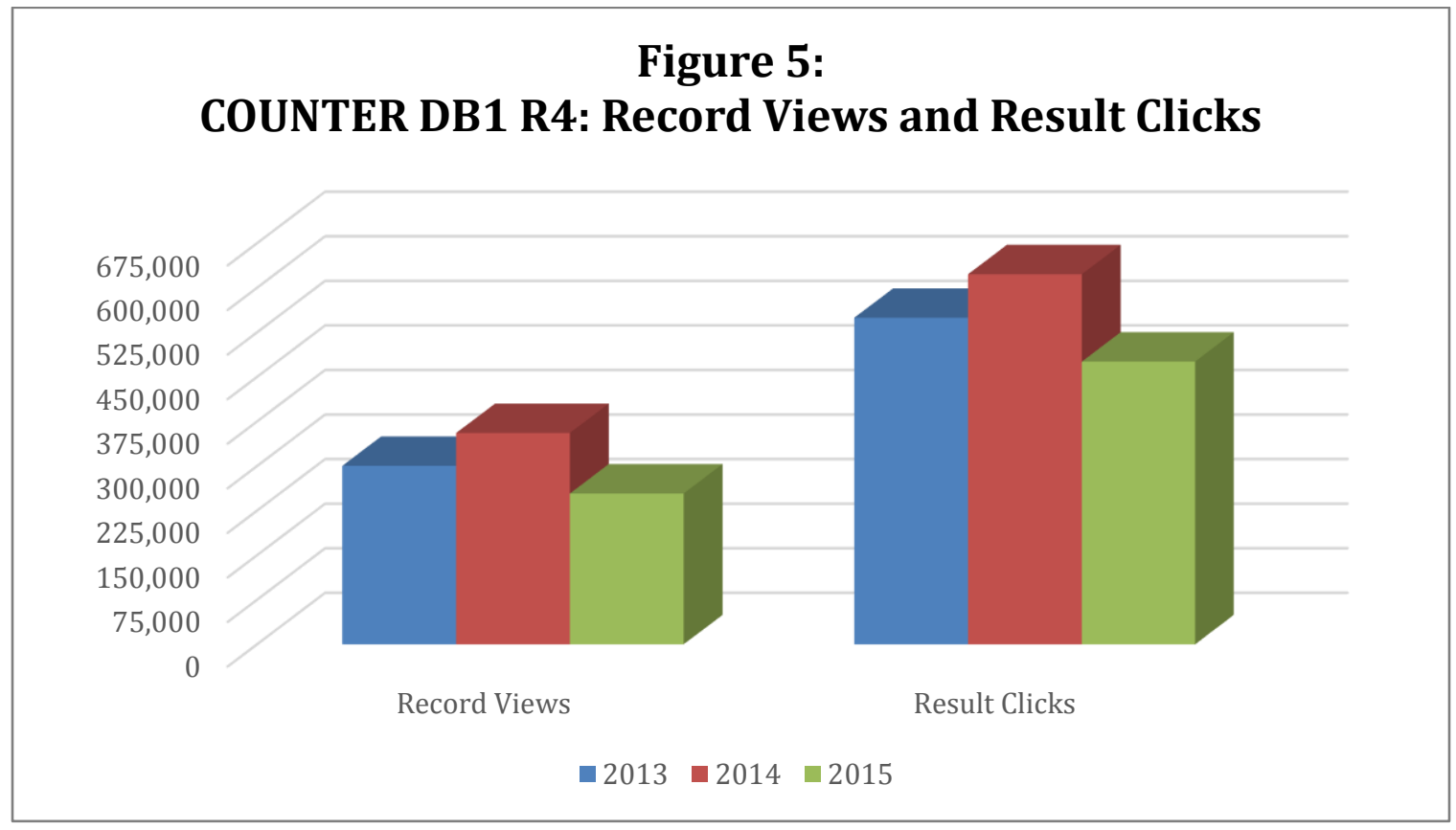

The last metrics examined to evaluate the impact migration to Primo had on online resource usage are from COUNTER Database Report 1 (R4) and consist of record views and result clicks. These two metrics provide information to help determine whether or not online resource usage increased post-migration. Whereas full-text article requests showed a small, but noticeable drop, result clicks and record views decreased even more. Record views in 2013 totaled 300,395 and in $2014,335,589$, for a two-year pre-migration average of 317,992. In 2015, the first postmigration year, record views dropped to 253,851 , a 20.17 percent decrease from pre-migration usage, also seen in Figure 5. This change was similar for result clicks, and is also shown in Figure 5. The calendar year 2013 saw 549,602 result clicks and 2014 had 622,821 result clicks; these numbers combined for a two-year pre-migration average of 586,212 result clicks. Again, in 
the first post-migration year, 2015, result clicks declined to 475,759, or an 18.84 percent decrease, very similar to the drop seen in record views.

The decline shown in data gathered from Journal Report 1 (R4) and Database Report 1 (R4) for journal and database usage illustrates that CWU's migration to Primo directly contributed to the drop in database and electronic journal usage. Full-text article requests, result clicks, and record views all decreased noticeably in the year post migration. It appears users are finding the resources they need in Primo as they are not turning to the databases by title and databases by subject web pages as often as they did pre-migration, but they are also not accessing as many articles as they did pre-migration.

How Primo has influenced the decline in full-text article requests and database result clicks and record views is still unclear and requires more research. In addition, determining what types of resources users are finding with Primo requires more research. The results of this study are consistent with other findings where a large universal drop in database use after migration to a Web-scale discovery layer was seen (Way 2010). Given that the Primo instance at CWU searches and displays resources available at all 39 current members of the Orbis Cascade Alliance, it is possible that users are finding, and requesting, articles or resources through other libraries in the Orbis Cascade Alliance that are more relevant to their research than current CWU holdings. Again, this question would require additional research, and if this speculation were found to be true, it would have a direct impact on holdings selection, especially electronic holdings selection, at CWU. Usage from other Orbis Cascade Alliance libraries would not have an effect on CWU's usage statistics as users from those libraries are not able to access CWU's databases or electronic holdings. Likewise, due to most license agreements borrowing requests are not generally filled using electronic holdings.

\section{Conclusion}

The hypothesis presented by the author that web page access to databases would be reduced after implementation of Primo, a Web-scale discovery layer, while online resource use would increase given the ease of discovering electronic resources was proven partially true. Web page views of database pages did decrease in the year following migration, supporting the author's hypothesis. However, online resource usage decreased in the year post migration, proving the second part of the author's hypothesis false. 
Web pages views of databases by title and databases by subject both decreased post migration, at 11.26 percent and 48.54 percent respectively. Both numbers are significant enough to conclude that Primo had a noticeable impact on user behavior, and that users, especially those who traditionally turned to the databases by subject page as a gateway to locating articles, found the information they needed within Primo without having to search for and in specific databases. That said, many users still continued to turn to specific databases to fulfill their research needs, as shown by the continued though slightly decreased views of the databases by title page. Nevertheless, further research is needed to determine if users turn to specific databases instead of or in addition to Primo.

The second part of the hypothesis was clearly proven false as usage of online resources did not increase, and actually decreased, during the Primo post-migration period. A comprehensive picture of this decline was shown with full-text article requests decreasing in the post-migration year compared with the two year pre-migration averages by 2.28 percent, result clicks by 18.84 percent and record views by 20.17 percent. This decline in full-text article requests and database usage is the more perplexing of the results; if fewer users are accessing full-text articles or database results, where are they finding their resources? These numbers would have remained consistent regardless if users accessed the results from Primo, directly from specific database interfaces, or from linking from open web sources such as Google Scholar. Additional, easily discoverable and accessible results from Orbis Cascade Alliance libraries may have a direct impact on CWU database use, and might be where some users are finding needed resources, but this possibility needs to be researched further. Likewise, another alternative idea, which would require additional research and may have led to decreased usage, is that some users may be locating information on the open web through open access journals, institutional repositories, or other freely available resources that meet their research needs.

Primo was found to have a significant impact on the way users discover information by causing a decrease in not only web page views for databases by titles and databases by subject, but also full-text article requests and database record views and result clicks as shown by COUNTER statistics. Only time will tell if these Web-scale discovery layers will have an impact on the role databases play in the library, though it seems for the foreseeable future, certain user groups will still turn to specific databases to meet their needs. 


\section{References}

Breeding, Marshall. 2012. "Looking Forward to the Next Generation of Discovery Services." Computers in Libraries 32 (2): 28-31.

Bull, Stephen, Edward Craft, and Andrew Dodds. 2015. "Evaluation of a Resource Discovery Service: FindI @Bham.” New Review of Academic Librarianship 20 (2): 137-66.

Central Washington University. n.d. "About CWU | Quick Facts.” Accessed January 11, 2016. http://www.cwu.edu/about/quick-facts.

Condit Fagan, Jody, Meris Mandernach, Carl S. Nelson, Jonathan R. Paulo, and Grover Saunders. 2012. "Usability Test Results for a Discovery Tool in an Academic Library." Information Technology \& Libraries 31 (1): 83-112.

COUNTER. 2016. "COUNTER Quick Guide: Result Clicks Record Views. A Guide for Librarians.” Accessed March 30, 2016. http://www.projectcounter.org/documents/Quick Guide.pdf.

De Rosa, Cathy, Joanne Cantrell, Matthew Carlson, Peggy Gallagher, Janet Hawk, and Charlotte Sturtz. 2010. "Perceptions of Libraries, 2010: Context and Community: A Report to the OCLC Membership.” Dublin, OH: OCLC Online Computer Library Center, Inc. Accessed June 29, 2015. https://www.oclc.org/content/dam/oclc/reports/2010perceptions/2010perceptions_all.pdf.

Fawley, Nancy, and Nikki Krysak. 2012. "Information Literacy Opportunities within the Discovery Tool Environment." College \& Undergraduate Libraries 19 (2-4): 207-14. Accessed December 23, 2015. http://digitalscholarship.unlv.edu/lib_articles/438.

Gottfried, John C. 2011. "Access to Business Research Resources Through Academic Library Websites: A Survey.” Journal of Business \& Finance Librarianship 16 (1): 1-32.

Jarrett, Kylie. 2012. "Findit@Flinders: User Experiences of the Primo Discovery Search Solution." Australian Academic \& Research Libraries 43 (4): 278-87.

Kornblau, Amy I., Jane Strudwick, and William Miller. 2012. "How Web-Scale Discovery Changes the Conversation: The Questions Librarians Should Ask Themselves." College \& Undergraduate Libraries 19 (2-4): 144-62.

Lundrigan, Courtney, Kevin Manuel, and May Yan. 2015. “'Pretty Rad': Explorations in User Satisfaction with a Discovery Layer at Ryerson University." College \& Research Libraries 76 (1): 43-62.

Mahoney, Jessica, and Susan Leach-Murray. 2012. "Implementation of a Discovery Layer: The Franklin College Experience.” College \& Undergraduate Libraries 19 (2-4): 327-43.

Nichols, Aaron, Amber Billey, Peter Spitzform, Alice Stokes, and Catherine Tran. 2014. "Kicking the Tires: A Usability Study of the Primo Discovery Tool." Journal of Web Librarianship 8 (2): 172-95.

Niu, Xi, Tao Zhang, and Hsin-liang Chen. 2014. "Study of User Search Activities with Two Discovery Tools at an Academic Library." International Journal of Human-Computer Interaction 30 (5): 422-33. 
Orbis Cascade Alliance. 2015. "Shared ILS Migration Complete!.” News Release, January 22. Accessed January 11, 2016. https://www.orbiscascade.org/sils-migration-complete/.

Tilley, Elizabeth. 2013. "Personalized Boutique Service: Critical to Academic Library Success?" New Review of Academic Librarianship 19 (1): 78-97.

Wang, Yongming, and Jia Mi. 2012. "Searchability and Discoverability of Library Resources: Federated Search and Beyond." College \& Undergraduate Libraries 19 (2-4): 229-45.

Way, Doug. 2010. “The Impact of Web-Scale Discovery on the Use of a Library Collection." Serials Review 36 (4): 214-20.

Williams, Sarah C., and Anita K. Foster. 2011. "Promise Fulfilled? An EBSCO Discovery Service Usability Study.” Journal of Web Librarianship 5 (3): 179-98. 